\title{
REGULATING GATV SYSTEMS: AN ANALYSIS OF FCC POLICY AND AN ALTERNATIVE
}

\author{
Harold J. Barnets and Edward Greenberg*
}

\section{INTRODUCTION}

CATV systems, like negotiable certificates of deposit and containerized rail transportation, hold a special place in the hearts of those who believe in free markets. All are innovations which developed before the government regulators of the respective industries knew quite what was happening. The innovators saw gaps in the existing services and-attracted of course by the opportunity to earn good rewardsremedied these by utilizing rather ordinary technology in an ingenious fashion.

With his faith in the market revived by such innovations, why would an economist ever recommend regulation? In certain situations, a free market is likely to produce undesirable results. In some of these cases, it may be possible to introduce regulations on the industry to improve its performance. ${ }^{1}$

There are several points to note about this economics approach to regulation:

(I) The economist, unlike the lawyer, is not concerned with whether some agency has the jurisdiction to regulate an industry. He assumes that this is a matter of procedure-that the necessary laws can be enacted, modified, or repealed as rational policy would dictate.

(2) The approach requires a spectrum of forecasts of how the industry might develop in the absence of regulation and under various systems of regulation. This, of course, is both difficult and beset with uncertainties.

(3) The economics approach requires that there be some definite way of appraising whether the industry is performing in a desirable fashion. The traditional criteria employed include such variables as prices and profits, internal efficiency, political effects, and degree of market power. ${ }^{2}$

In some circumstances it is possible to agree on a set of very explicit goals which, if achieved, will be considered a satisfactory outcome. Examples are locating a firm in each city or achieving a six per cent rate of return. Public utility regulation of electric power may be of this character. In other situations, however, the specification of very explicit goals may be more difficult and even quite undesirable. When there is uncertainty with respect to demands as well as major innovations and other supply changes, and when there is interaction between these forces, too explicit a goal

\footnotetext{
- Professors of Economics, Washington University. Our thanks are due to Professor Marshall Hall for his comments on an earlier draft.

${ }^{1}$ This is the view of regulation presented in Coase, Discrission, 54 AM. Econ. Rev. 194 (1964).

2 These and other criteria are thoroughly discussed in Posner, Natural Monopoly and Its Regulation, 21 StAN. L. REv. 548 (1969).
} 
may become an obstacle to the further development of an industry, in the form of a straitjacket preventing desirable change. Television regulation is in this position. It is dangerous to regulate restrictively a highly dynamic sector of the economy and society.

Regulators might do best to keep the situation flexible, to create a process which is capable of accommodating undirected change. It might be desirable to foster rather than oppose the free entry conditions which usually characterize competitive markets. Innovations might then appear which promise to improve and extend the industry's performance far beyond what was possible when goals were originally set. The FCC's attitude toward the regulation of CATV systems provides an interesting case study of these considerations.

\section{Television Regulation}

The Communications Act of 1934 as it applies to broadcasting is an example of Congress's choosing to set up a process and general objectives rather than narrow goals. A new technology was being introduced, and its implications were not clear. It would in such circumstances be unwise to attempt to set restrictive goals for the industry. Rather, an organization was set up, the FCC, which would be able to acquire expertise in this new area of science, technology, and public affairs. It would regulate with a light hand as required by changing conditions. Because of the uncertainty, Congress stipulated general and broad purposes for the regulators of the communications industry:

For the purpose of regulating interstate and foreign commerce in communication by wire and radio so as to make available, so far as possible, to all the people of the United States a rapid, efficient, nation-wide, and world-wide wire and radio communication service with adequate facilities at reasonable charges $\ldots .{ }^{3}$

In broadcasting Congress directed the bare minimum of control. The plan called for regulation of spectrum use: the allocation of channels, noninterference, and assignments among competing applicants. ${ }^{4}$ But, by not designating broadcasting firms as common carriers, Congress relieved the FCC from concern with profits, prices, quality, and the many other variables that public utility commissions usually worry about. Reciprocally, to balance these freedoms, Congress also was careful to deny to licensees any monopoly rights either for license renewal or against competitors. ${ }^{5}$

For the important problem of allocating television channels to cities, the Com-

\footnotetext{
${ }^{3}$ Communications Act of 1934,47 U.S.C. $\S 15$ I (1964).

4 Id. \$303. This minimum amount of regulation was based upon the assumption that the market mechanism would not be used for the purpose of allocating spectrum; see Coase, The Federal Commutnications Commission, 2 J. LAw \& EcoN. I (1959).

${ }^{5}$ Communications Act of 1934,47 U.S.C. $\S 301$ (1964).
} 
mission was faced with some difficult choices. Because television signals can interfere with each other, and because there were alternative uses for the same spectrum space between television and, say, airlines, marine communications, and taxicabs, the FCC had to allow one use and prohibit others. But the FCC went further than making assignments in instant cases. It designed and blueprinted the future, by reserving a certain amount of spectrum space for television. And it determined that this space would be allocated geographically in accordance with the following set of priorities: ${ }^{6}$

(I) "To provide at least one television service to all parts of the United States."

(2) "To provide each community with at least one television broadcast station."

(3) "To provide a choice of at least two television services to all parts of the United States."

(4) "To provide each community with at least two television broadcast stations."

(5) "Any channels which remain unassigned under the foregoing priorities will be assigned to the various communities depending on the size of the population of each community, the geographic location of such community, and the number of television services available to such community from television stations located in other communities."

Not only did the FCC arbitrarily reserve a very large, specific volume of the VHF and UHF spectrum space for future television use even though there were other contemporary and prospective users for the frequencies, but arbitrary decisions also determined the scheme and the specific assignments to cities. There was no market or other objective process set up to resolve these key questions. There was no solid information base. The questions were decided within the FCC itself for the next generation and beyond. A heavy hand from the past was to constrain the future of radio and television.

Thus, the vague Congressional direction was turned into rather detailed and restrictive plans by the Commission. At the time of their adoption they may have appeared to be not unreasonable. But these blueprints are in conflict with what the public now and in the future could procure from television.

We consider briefly some of the things that television presently does well and some of the things it does poorly. There is little doubt that television in the United States (as in other developed countries) has developed great rapport with a substantial percentage of the population. Television sets are now in more than ninety-five per cent of U.S. homes. About sixty per cent of these sets are turned on during prime time. In the United States this large audience has been attracted in major degree by entertainment programs of mass-audience appeal. In addition, television has presented extensive news and public affairs programs. All this may be viewed as a plus. On the other hand, television has not done a very good job of

\footnotetext{
${ }^{6}$ Amendment of the Commission's Rules, Regulations and Enginecring Standards Concerning the Television Broadcast Service, I7 Fed. Reg. 3905, 3912 (1952).
} 
reaching minority audiences. Those audiences may represent a small percentage of the population, but they are large in absolute numbers. For example, a three per cent audience in the United States would comprise six million people. Politicians, small advertisers, and others have found television too expensive for their budgets. Frequent advertising messages and other interruptions have come to occupy about twenty-five to thirty per cent of all broadcast time. Perhaps the best way to summarize the situation is to say that there is a lack of diversity in television programming. The various stations and networks tend to present programming aimed at the same mass audiences, and virtually all offerings are tendered through a barrage of advertising noise and interruptions.

It seems to us that these defects could be remedied by a more competitive and greatly enlarged system. Such a system should have the capacity to deliver a much larger number of television signals to each home. It should be open to much wider diversity of program preferences. It should facilitate informational, cultural, and educational services without pre-empting transmission avenues available for private use. It should make possible programs with no advertising, or reduced and less disruptive advertising, for those who would prefer and be willing to pay for them.

Technology for such a system has long been available. It has increasingly become economically feasible and viable through the development of the wired city and nation. ${ }^{7}$ However, the Commission has become increasingly repressive of those segments of the broadcasting industry which have been initially developing wiretelevision technology and service. These are the CATV (cable TV or community antenna TV) systems which, while they represent only a pioneering, primitive form of the potential of wired cities, are nevertheless an important stage in their evolution and maturation. We now review and appraise FCC regulatory behavior with respect to CATV and offer recommendations for revision.

\section{II}

\section{Short Description of CATV Technology}

The simplest CATV system consists of a tall antenna, to pick up over-the-air signals of broadcasting stations, and a cable, which delivers the multiple signals to individual homes. Modern CATV systems can relay programs from distant places, originate their own programs, and improve signal quality for viewers. For these services-program importation, program origination, and signal improvementCATV operators charge a subscriber about $\$ 5$ per month.

The advantage in using cable for delivery is that it is capable of carrying a very large number of channels without the interference that would occur if the signals were sent over the air. The original signals may come from broadcasting stations, microwave relays, long distance cables, or satellites, or they may be inexpensively

\footnotetext{
${ }^{7}$ Barnett \& Greenberg, A Proposal for Wired City Television, xg68 WASH. U.L.Q. I, reprinted in Brookings Instirution, The Radio Spectrum: Its Use and Regulation I (ig68).
} 
introduced directly into the cable system. The delivery of the signal to the home takes place in a manner which permits a large number of clean, strong signals. These signals are compatible with the reception capabilities of present television sets, as well as those of potentially improved and less expensive ones, and they do not require spectrum space in the scarce VHF or UHF band. Most U.S. CATV systems have a twelve-channel capacity, but systems with twenty or more channels are now being installed; there is no practical limit on the number of cable channels.

\section{III}

\section{Regulation of CATV: The FCC ig66 Second Report and Order}

For all practical purposes the FCC regulation of CATV began with the rg66 Second Report and Order, where the following restrictions on CATV companies were introduced: ${ }^{8}$

(r) Compulsory carriage: A CATV system must carry the signals of local stations.

(2) Nonduplication: A CATV may not duplicate the prime-time network programming of a local station by importing such programs during the same day.

(3) Major-market/distant-station policy: Under this rule a CATV system may not import signals into the Ioo largest TV markets (where the great bulk of U.S. population resides) unless it is given permission by the Commission, following a hearing for determining whether CATV operations in a particular market "would be consistent with the public interest, and particularly the establishment and healthy maintenance of UHF television broadcast service."

(4) Program origination. The FCC desired to eliminate or greatly limit the origination of programming by CATVs. It stated that it would ask Congress for legislation on the subject.

It should be noted that previous to the Second Report, there were no restrictions on CATV operation. Provisions ( $I$ ) and (2), while perhaps inconvenient to some smaller CATV systems, did not materially affect the industry's growth possibilities. But (3) and (4), if they denied imports and prohibited program origination, would have been devastating. If CATVs in the first roo TV markets were denied permission both to import distant programs and to originate their own, they would not be able to attract subscribers, except where over-the-air reception was particularly bad. The public-service capacity and the economic viability of the CATV industry would be destroyed and its development stopped.

\footnotetext{
${ }^{8}$ Amendment of Subpart L, Part 9I, to Adopt Rules and Regulations to Govern the Grant of Authorizations in the Business Radio Service for Microwave Stations to Relay Television Signals to Community Antenna Systems (Second Report and Order), 2 F.C.C.2d 725 (I966) [hereinafter cited as Second Report]. For a more detailed discussion of the Second Report sec Greenberg, Wire Television and the FCC's Second Report and Order on CATV Systems, Io J. LAw \& Econ. 181 (1967).

${ }^{\circ}$ Second Report, supra note 8 , at 782 .
} 
The result of the order, of course, was a mad scramble by CATV operators to obtain permission to import distant signals through the required application and hearings. Frequently the CATV applicants were successful. The Commission then terminated these hearings in December rg68 with the following comment:

Clearly, then, it makes little sense to continue these lengthy, complex evidentiary hearings on the economic impact issue-hearings which, we also note, have imposed a considerable burden upon the Commission and the participating parties. ${ }^{10}$

\section{IV}

\section{Regulation of CATV: December rg68 Proposed Rule Making}

In its introductory comments to the December 13 notice, the Commission proposed a proceeding

to explore the broad question of how best to obtain, consistent with the public interest standard of the Communications Act, the full benefits of developing communications technology for the public, with particular immediate reference to CATV technology and potential services, and the nature of any regulations and/or proposed legislation that may be necessary or desirable to further this goal.11

Quoting itself and others, the Commission indicated that it now recognizes the role that wire transmission can play in a greatly expanded television system:

It now appears that cable technology may be on the verge of expanding system capacity to 20 or more channels, and that a variety of new services to the public are envisioned. ${ }^{12}$

CATV program origination offers promise as a means for increasing the number of local outlets for community self-expression and for augmenting the public's choice of programs and types of service, without use of spectrum. . . The CATV system is not handicapped by limited channel capacity, having I2 channels in comparison to the one channel of the individual broadcaster, and thus has the technical flexibility to provide different types of programs or services on some channels without affecting the service simultaneously provided on other channels. ${ }^{13}$

In conclusion, the promise of cable television remains a glittering one. While progress towards realizing this promise has been slow, there is now an abundance of venture capital ready and able to extend cable television throughout the City. ${ }^{14}$

${ }^{10}$ Amendment of Part 74, Subpart K, of the Commission's Rules and Regulations Relative to Community Antenna Television Systems, 33 Fed. Reg. I9028 para. 4x (F.C.C., released Dec. I3, I968) [hereinafter cited as CATV Inquiry].

${ }^{11} I d$. para. 2.

${ }^{12}$ Id. para. 4 .

${ }^{13}$ Midwest Television, Inc., 13 F.C.C.2d 478, 505-06 (1968), as quoted in CATV Inquiry, stspra note ro, para. 5 .

14 Letter from the Chairman of the Mayor's Advisory Task Force on CATV and Telecommunications to the Mayor of New York City, Sept. 14, 1968, as quoted in CATV Inquiry, supra note ro, para. 7. 
In view of these statements, it is rather surprising to find that, as will be shown below, the Commission's actions are designed to inhibit CATV growth severely.

Completely reversing its previous position on program origination, the Commission now finds that, "for now and in general, CATV program origination is in the public interest." ${ }^{\text {"15 }}$ However, although the FCC further proposes to require that CATV systems operate as local outlets by originating programs, each CATV is limited to one channel for its programming. Rules will be considered to determine how the program origination is to be financed-whether through present subscribers' fees, advertising, or by a supplement to the basic rate for CATV service. Finally, the possibility of common-carrier operation (presumably the nondiscriminatory provision of service at published rates to all who request it) on remaining channels is to be considered.

Import of signals into the top roo markets, where the great bulk of the population resides, has been further restricted. In the hearings instituted by the 1966 Second Report, the CATVs had frequently won permission to import. Under the new system, however, hearings are abolished; in their place is imposed the condition that a CATV system desiring to import a signal into a major market must obtain retransmission permission, on a program-by-program basis, from the broadcasting station. The practical effect of the rule should be noted. Because of their agreements with program suppliers, broadcasting stations do not have the legal right to grant such permission. Thus, although the delivery of distant signals has been the most important of CATV's selling points, the rule effectively bars the systems from importing.

Clearly the growth possibilities are stopped or severely limited by the restrictions on imports and program origination. The FCC action was immediately and widely understood as being in protection of traditional broadcasting-an effort to eliminate CATV as a competitive threat to broadcasters. What is surprising, in view of the Commission's clear desire to suppress CATV, is its defense of the proposed and interim rules.

The FCC case rests on what it calls "unfair competition," but this use of the term is unreasonable and objectionable. At paragraph 37 of the Notice of Inquiry it is pointed out that the unfair competition in question is not related to the Federal Trade Commission Act, ${ }^{18}$ the Compco case, ${ }^{17}$ the Sears case $^{18}$ or the viewpoint of the copyright owner. "Rather, our concern is the public interest in the broadcast field-'the larger and more effective use of radio ....'"10 Thus an existing legal concept was emptied of present and historical content, provided with new meaning,

\footnotetext{
${ }^{15}$ CATV Inquiry, stupa note 10, para. 13.

${ }^{16}$ Id. para. 37.

${ }^{17}$ Compco Corp. v. Day-Brite Lighting, Inc., 376 U.S. 234 (1964).

${ }^{18}$ Sears Roebuck \& Co. v. Stiffel Co., 376 U.S. 225 (1964).

${ }^{10}$ CATV Inquiry, supra note 1o, para. 37 .
} 
and made the lever to destroy a promising innovation-all without benefit of either statute or court decision! ${ }^{20}$

The Commission reasoning was actually provided in the Second Report. ${ }^{21}$ The Commission is concerned that the growth of CATV might displace the development of new or prospective UHF stations which the FCC has long hoped would improve the industry's performance. The Second Report was explicit and understandable as an attempt to protect such stations: the FCC would look into the situation in each case to decide whether a prospective CATV system would, by competitive offering, prevent the development of an existing or prospective UHF independent station. Permission to import signals would depend on no such injury being shown.

In its December I3 notice the FCC says that CATV imports will require retransmission permission from the originating station in order to prevent unfair competition with local stations. This is without economic sense. Let us test whether the FCC desires to improve competition, as it says, or really desires to eliminate the CATV competition. Suppose, for example, that a CATV proposes to import the signal of station $A$ into a market which contains a struggling independent UHF station, $B$. The competition is between the CATV and $B$ for the same audience. Now the FCC requires that the CATV obtain the permission of $A$. In the absence of collusion or conspiracy $A$ 's position is clear; he will desire to have his signal viewed by as large an audience as possible since his advertising rates and prestige depend on the number of viewers. If it were legally possible, he would be delighted to give permission, and he might require only a nominal fee. $\mathrm{He}$ would not charge so much as to lose the CATV pickup. The CATV would continue to import and operate. To make the protection of the UHF station effective, the retransmission consent would have to be virtually impossible to obtain or too expensive to permit the CATV to be viable. The FCC achieves this outcome by requiring explicit, unconditional permission on a program-by-program basis. It is apparently not possible for stations to give more than a quitclaim type of permission-by which stations give only such rights as they possess. But this does not satisfy the FCC unconditional and program-by-program stipulation. Thus the FCC effectively denies the CATV the ability to import the signal. ${ }^{22}$

Whereas previously a CATV might convince the Commission that the UHF station would not be adversely affected in some particular market, the new rule precludes even this opportunity for program importation. The effect of the new role is to eliminate CATV program imports, restricting even the largest cities to a fairly

\footnotetext{
${ }^{30}$ See 2 J. Bonbright, Valuation of Property ir7o (r937): "[T] he vice of traditional law lies . . . in its tendency to permit shifts in meaning that are inept, or else that are ill-defined because the judges that make them will not openly admit that they are doing so."

${ }^{21}$ Second Report, supra note 8, at 778-8x.

${ }^{22}$ See Fortnightly Corp. v. United Artists Television, Inc., 392 U.S. 390 (I968). In the Fortnightly decision, the Supreme Court determined that CATV pickup and conveyance to customers was not infringement of the copyright statute. There is widespread belief that the FCC retransmission rule is a back-door attempt to overcome the Court's ruling in this case.
} 
narrow choice of programs. ${ }^{23}$ For example, if the rule proposed in the notice becomes fully effective, among the markets limited in ultimate growth to fewer than six commercial channels are Pittsburgh, Cincinnati, Buffalo, Dayton, Columbus, Johnstown-Altoona, Memphis, Charlotte, Toledo, Birmingham, Nashville, Omaha, Rochester, and Terre Haute.

Another aspect of the new rule which makes it appear that the Commission is not attempting to protect struggling broadcasters from unfair competition so much as it is trying to protect all broadcasters in large and medium size cities from any CATV competition is the discriminatory application favoring CATVs operating in small markets. These systems are allowed to import signals sufficient to increase their carriage to three networks, one independent, and one ETV station without retransmission permission. Based upon the FCC Rules, it is not unfair competition when CATV systems in small markets import signals, but it is unfair competition when the same thing happens in larger markets! The FCC's desire to protect broadcasters from CATV-import competition in large markets is readily apparent. ${ }^{\mathbf{2 4}}$

\section{V}

\section{Description of a Policy Alternative: If CATV Were Permitted} to Develop Rather Freely

The FCC policy has been to foster the development and growth of VHF and UHF broadcasting stations with an emphasis on local broadcasters. Additionally, it has been severely to restrict CATV and pay-TV innovations to very subordinate and supplementary roles in order to protect broadcasting stations and their FCCdesignated primary role in television. Now let us consider an alternative policy in which the CATV innovation is not relegated to a minor role. We shall consider what would be the outcome if Congress and the FCC simply permitted CATV to develop rather freely, guided by technology, the market motives of entrepreneurs and consumers, and the usual laws and actions of states and communities.

Then in Part VI below, we shall appraise this outcome against such public interest criteria as quality and volume of service to the public, effects on freedom in economic sectors and politics, and localism. Such examination will shed light upon the desirability of the I966 and I968 FCC measures concerning CATV.

\section{A. Assumptions: Imports, Carriage of Local Stations, and Program Origination}

(I) Signals will be imported, subject to statutory copyright license. The CATV industry has developed free of copyright liability for the importation of programs from elsewhere. ${ }^{25}$ Congress may, however, enact legislation which will make CATVs

\footnotetext{
${ }^{23}$ The question of CATV program origination is taken up below.

${ }^{24}$ For more detailed appraisals of the FCC's December 13, I968, Proposed Rule Making, see Statement of Harold J. Barnett before the FCC on Parts III and IV of the Notice of Proposed Rule Making in Docket 18397 , February 3, 1969; Statement of Harold J. Barnett Before the Subcomm. on Communication and Power of the House Comm. on Interstate and Foreign Commerce, May 21, 1969.

${ }^{25}$ Fortnightly Corp. v. United Artists Television, Inc., 392 U.S. 390 (1968).
} 
liable for copyright payment; the question is now in Congressional committee. It is possible that this legislation, if enacted, will provide for compulsory licensing under which a CATV system will have the right to import freely upon payment of a percentage (say two per cent) of its subscription revenues to the Register of Copyrights or some other agent for distribution among claimant copyright holders. A CATV enterprise would surely elect to make this payment, or even a higher one, for imported programs in order to avoid significant loss of subscribers. The subscriber reduction in the absence of imports would certainly cost the CATV operator more in lost revenue than the statutory copyright fee which he avoided; and he probably would not be able to obtain equivalent substitute programming at such a low price.

(2) Local stations will be carried, and there will be simultaneous duplication protection. CATV systems would accept these conditions. They have more potential channels than they use; and there is no real advantage to the CATV in simultaneously duplicating local programs by importation from a more distant station.

(3) Program origination will not be limited by the FCC.

In summary, our assumptions are that CATVs will import and originate programs, and that local stations will be given the benefit of carriage on wire, while being protected against simultaneous duplication by the CATV imports.

\section{B. CATV Would Grow Rapidly}

The pattern of CATV development in the absence of FCC restrictions would then be rather clearly apparent. This may be read from the record of past CATV growth. The prospect is for fairly rapid, continuous development. Rapid does not mean instantaneous-applications take time, as do selling and building. The rate of subscriber acquisition would be perhaps three per cent to ten per cent of area homes in each year. People would subscribe to CATV service for more programs and better quality signals, although the combination of these two elements would vary according to the local situation. The rural or small-town subscriber who has little or no TV service off-the-air has strong incentive to subscribe. The recent CATV record in such communities shows that one-third to one-half of the home owners have been willing to pay $\$ 50$ to $\$ 60$ per year for six to twelve high quality signals. Metropolitan areas residents initially have less incentive to subscribe, since they already receive three networks and perhaps an independent station or two. But a large fraction of these viewers would also ultimately subscribe. Their entertainment budgets are higher than their rural cousins', and the fees would burden them less. Moreover, their several signals would be improved in quality, an important gain in some metropolitan areas which are plagued with TV ghosts. And ultimately even they are interested in the idea of additional signals brought from distances and the possibility of new CATV programs without advertisements. In summary, CATV services would be likely to grow and flourish in all types of areas. 


\section{CATV Industry Organization}

\section{r. CATV Chains Would Develop and Broadcasters Would Enter CATV}

Among existing firms, $\mathrm{H}$ and B American, Cox, Time-Life, TeleVision, TelePrompter and General Instrument are examples of major CATV chains, and there are still other important firms. One reason for chains is that this new business is rather a specialized one, and companies have acquired expertise in negotiating franchises and setting up one or more CATV systems. A second reason lies in the fact that a CATV system possesses aspects of "natural monopoly," and experienced CATV firms, including broadcasters, have an advantage. Finally, there are genuine scale economies in operation. One of these occurs in relaying distant signals to CATV systems. Obviously, microwave carriage of a signal from Chicago to St. Louis could economically drop off the program at intermediate points. Other economies of scale occur in management overhead and in program acquisition and creation. The substantial merger movement in CATV testifies to the advantages of larger scale.

The tendency toward development of CATV chains has implications for networking. The CATV chains would begin to originate programs with their own advertisements. Eventually they would engage in networking, using both CATV systems and broadcasting stations as outlets. Such a use of CATV outlets could allow a degree of circumvention of the FCC rule limiting the numbers of broadcast stations which a network company is permitted to own. Moreover, the spread of CATV systems would increase the number of potential outlets available for networking, so that the number of networks could increase beyond the existing three.

\section{Franchises and Monopoly Rates and Profits}

The record is clear that CATV companies can earn high rates of profit at the conventional subscription fee of $\$ 5$ per month. CATV is a natural monopoly in whatever localized area it serves. In such a situation, (a) although there may be several initial applicants and franchise holders, the incentive to merge is very great; $(b)$ if all stayed there would be a tendency toward price wars, and all but one would probably fail; and $(c)$ it is not likely that another firm will enter if one is already well started or entrenched.

In general, municipalities have chosen not to regulate CATVs as a public utility by limiting their rates of return and profits in exchange for a monopoly privilege in all or part of the community. ${ }^{26}$ Although the CATV companies normally have received nonexclusive franchises to lay their wire, CATV monopolies have usually resulted. Municipalities are now becoming aware of how profitable the CATV system is likely to become under monopoly conditions and are beginning to exact large payments in exchange for a CATV franchise. More and more com-

\footnotetext{
${ }^{28}$ Connecticut, Rhode Island, and Nevada have enacted public utility statutes for the regulation of CATV.
} 
munities will procure high franchise fees, either from negotiation or by requiring CATV applicants to bid against each other. Franchise agreements which would provide fifty per cent or more of revenues to the city are possible. If city governments and the public were well informed, the municipality could extract the prospective monopoly gain in the franchise agreement and retain rights for renegotiation in the event of unforeseen favorable developments. ${ }^{27}$

If knowledgeable, the municipalities tend to be so impelled by their chronic, sometimes desperate, shortage of revenues. But this propensity prejudices the major question of whether the CATV should not have been induced to charge a much lower rate in the first place to avoid compromising important social policy. A preferable policy might be to require that CATV subscriber rates be closer to cost of service plus a reasonable return on capital, either by knowledgeable rate regulation or by contriving a more competitive condition in supply of CATV services. At lower prices more homes would subscribe, permitting still lower rates in this declining-cost industry. Monthly subscriber rates could fall to half or even less, relative to their present level, thus fostering favorable social effects from enlarged communication capacities.

In the absence of improvement in the leadership of the FCC, upon which Congress had placed faith and reliance for the evolving radio and TV industry, it is difficult to see how lower prices could come about. The CATV company prefers local monopolies and high subscriber rates. The city council wants a high tax take. The companies which own movie theaters, sports palaces, TV stations, and other entertainment media would prefer a (prohibitively) high rate. And the prospective subscribers are unorganized and unaware.

\section{CATV Operations}

\section{CATV Sale and Gift of Channel Space and Time}

We expect CATV systems to be willing to sell and/or give channel time to public bodies, advertisers, politicians, ETV systems, and others. Such sale or gift will markedly enlarge the opportunities and choices available to local bodies. In big cities the time availabilities on TV stations are so meager and the rates so high that most local groups are frozen out of TV, although this is somewhat less true in the smaller cities. Since CATVs have excess channel capacity, they would donate some of these channels for education or other public purposes if required to do so in order to acquire a franchise.

\section{CATV Program Originations}

If the CATV operator can inexpensively microwave into his service area the expensive programs produced elsewhere, in general he will not desire to expend

\footnotetext{
${ }^{27}$ For thoughts on how the municipality could procure CATV service for its citizens at competitive prices in spite of the industry's natural monopoly characteristics, see Demsetz, Why Regulate Utilities?, II J. LAW \& ECON. 55 (I968).
} 
large sums on production himself. But there are reasons for him to originate programs:

(a) His offer of programs accompanies his effort to sign on subscribers. These are usually inexpensive offerings (weather, time, news-ticker, local government meetings, citizen and club meetings) rather than the usual TV entertainment fare, but occasionally more expensive efforts may also be tried.

(b) The CATV systems which are very profitable might offer "public service" programs as present broadcast stations do, in order to protect their licenses and profits and avoid criticism. As the Cox-Johnson report on renewal of Oklahoma broadcast licenses indicates, however, these public service offerings are likely to be meager and inexpensive. ${ }^{28}$ But unlike the case of broadcasters, the CATV operator is likely to have extra channels. He will volunteer or can be persuaded to offer free time (and good time) for public service broadcasts, provided this does not involve significant program expense.

(c) CATV systems may be affiliated with firms which own program material. If this material were available to the CATV firm at low cost, the CATV might offer it as a further device to retain present subscribers and attract new ones.

(d) In a two-station market, the CATV firm could conceivably acquire an affiliation status with the third network, making the third network's programs available to the CATV. But this is not really program origination, since the CATV could have obtained the same network program by importing it.

(e) Finally, the CAIV firm would originate programs if it were paid to do so by advertisers whose messages it would carry, or by pay-TV (per program) for those subscribers who would be willing to pay the extra fee. This would lead to networking or syndication, since there are obvious scale economies in program supply.

\section{Advertising and Pay-TV Revenues}

The last-mentioned point above could turn out to be very important. How will a CATV operator behave, assuming the usual profit motives? Specifically, how will he treat imported programs if these would divert some viewers from his own advertiser sponsored or pay-TV programs? Even if these latter offerings would appear to provide an increment of advertising or pay-TV revenues above cost, he still will not choose to eliminate all imported programs in order to increase the viewing of his own programs from which he gets advertiser or special fees. So doing would cause him to lose subscribers or would prompt the entrance of a competing CATV system with imported programs.

Within this constraint of holding subscribers he will make a calculation regarding long-term incremental profits from advertiser-sponsored program origination. Very early he will sell low-cost advertising spots to local merchants, and once he has a large list of subscribers, it will become profitable to expand this revenue base and

\footnotetext{
${ }^{28}$ See statement of Commissioners Kenneth A. Cox and Nicholas Johnson, Broadcasting in America and the FCC's License Renewal Process: An Oklahoma Case Study, I4 F.C.C.2d I (1968).
} 
try for regional and national ads. Advertisers should be willing to pay for the viewing of CATV subscribers, although initially at rather low rates. There is already a national system of so-called "advertising representatives," who funnel spot ads from the major advertising centers to local TV and radio stations, and they could easily serve the more developed CATV companies.

Further, the CATV will be pleased to commence pay-TV for selected programs on otherwise unused channels. It will find it far less expensive to provide technical and financial control and billing for a wire pay-TV operation than would an alternative pay-TV enterprise in over-the-air broadcasting. It is also likely that a combination of advertiser sponsorship and pay-TV will develop, in which special channels and programs will carry limited and unobtrusive advertising and also require extra payment from the subscriber. This combination of both advertising and viewer revenues already occurs in newspapers, magazines, playbills, European theaters, and sports parks.

We think that the foregoing-major program origination on pay-TV and large scale advertiser sponsorship-would tend to occur only after the CATV has become a successful enterprise and built up its subscriber list. Program origination with advertisements or special payments from subscribers can become financially significant only when there is a significant subscriber list which can be exploited for these additional profits. Until the subscriber list is built up, neither advertising revenues nor special payments could be very large, while the cost of arranging for or producing the programs may be substantial. On the demand side, the revenue (from advertiser or special pay) is likely to be proportionate to the number of subscribers; while the costs of overhead and programs originated will, in some cases, be invariant or increase very slowly relative to subscriber numbers. Also, the required capability and effort to produce programs or to arrange for their production or procurement is large and specialized.

\section{E. Effects on Broadcast Industry}

\section{Stations}

How much fragmentation of station audience would there be if CATVs could import freely? With simultaneous duplication protection and compulsory local carriage as assumed, the bulk of the populace would still watch the network affiliates on wire or over-the-air. The distribution of TV viewing would approach the Chicago, New York City, or Los Angeles pattern. There would be some increase in watching per thousand homes and some increase in viewing hours per day per home. There would be a relative reduction in the watching of network stations. Since TV advertisers outlays would be increasing each year from population and income growth, network-affiliated station revenue would probably not fall, although it would increase more slowly than in recent years.

CATV would compete for local advertising revenues. Independent stations 
which have not built up local identificaiton would thus have an additional competitor on local advertisements and could lose ground. At the national level, however, spot advertisers now on the affiliated and independent stations would maintain advertising volume there, although they would put some advertising on CATV also. For national advertisers, CATV systems have the disadvantage that they provide smaller viewing audiences, are spotty in coverage, and weak in programming.

UHF stations would be hurt by audience fragmentation, but they would also be helped by improved reception on the wire, without the need for an antenna or the necessity of switching to a UHF tuner. A marginal UHF station might prefer, if enough of the homes were wired up, to save \$100,000 per year in transmission expense by leaving the air and going directly onto the wire, if it could arrange this. Whether the UHF would then be viable depends primarily on how viable it was before CATV competition, and its ability to withstand any reduction in revenues and retardation in growth.

What about a very small town? Its stations are already marginal because of small circulation. If the CATV brought in distant programs, then audience fragmentation could occur and be significant: $(a)$ if the network advertiser did not buy distribution on the affiliate in the small town, viewers would tend to watch the imported network programs which are usually more popular than locally originated programs; $(b)$ if the town did not already have all three networks, some people would watch the imported network program rather than a competing local network program; and $(c)$ at the nonnetwork hours, the imported signals from big cities might be watched in preference to the local programming.

In conclusion, what this all adds up to for television stations, in good part because of network dominance in programming, is the following: (a) network stations will remain viable, and their financial burden from audience fragmentation is likely to be less than their gains from long-term growth; $(b)$ nonnetwork stations may experience more audience loss from fragmentation, and their finances might stabilize or turn down; $(c)$ new UHF nonnetwork stations may experience still more significant financial losses from imported signal competition, and despite an offsetting financial and viewing gain from being carried on wire, net reduction in viewing and finance is likely; and (d) while CATV will provide better pictures, imported signals, more diversity, and service for minority tastes, it will not greatly affect the distribution of television mass-audience viewing, given our assumptions on consumer freedom, compulsory carriage of local signals, and duplication protection.

\section{National Networks}

In any city which does not have the second or third network, it would pay that network to have its program relayed to the CATV. If the CATV is owned by a network-affliated broadcast station, the broadcaster may decide to import his own signal so he can include that audience count in his advertising rates. And, 
where a CATV has more than seventy per cent of the area population on its subscriber list, it might pay the networks to consider discarding their local affliates and using the CATV directly-assuming, as is usually the case, that the local station gets thirty per cent of the network billing while the CATV makes no charge.

But the matter is much more complicated than it appears. The national network advertiser pays the sum of the local stations' network rates, of which the network keeps about seventy per cent. If the CATV microwaves in at its option, then how is the network going to charge the advertiser for that circulation? It is possible that if there is no local network outlet, the local CATV will try to charge the network for carrying in the signal. Thus there may be an important change in the arrangements between the network and the local stations. The market would now include CATV as a competitor of the local station for network affiliation, if the city and environs are largely wired up. The CATV could afford to charge the network much less than could the station for carrying the network programs and advertisements. This suggests that networks and stations would be likely to move strongly into CATV ownership and operation if the FCC continued to permit this and if CATV were liberated to grow more rapidly.

Concerning networking finances, these could be expected to improve. The three networks are dominant sources of television programs and major recipients and outlets for national advertising expenditure. They are more highly skilled in producing and procuring TV performances and in national advertising sales than any other organizations in the world. They are also entrenched in their positions by long-standing business relationships, large program libraries, residual rights, and technical staffs and skills. With increase in the scale of national television offerings and viewing-ultimately an enlargement of the market for television entertainment and other services-their own financial prospects will also be larger. This assumes, of course, that their large size and power have not rendered them sterile and inflexible for dealing with new opportunities and competition.

\section{VI}

Appraisal of the Policy Alternative: Effects on Public Service and Programs for Viewers

Under present policy, the average number of commercial TV channels allocated to the top 100 markets is about as follows; these numbers include both VHF and UHF allocations, whether presently in use or not:

Top 50 markets

Next 25 markets

Next 25 markets

Top roo markets

\section{Average allocation per market}

6

5

$\frac{4}{5^{1 / 4}}$ 
In addition, the FCC has reserved for noncommercial use an average of about one and one-half channels (mostly UHF) in each of the top roo markets. This aggregate allocation of commercial and noncommercial television channels represents the total station availability for over-the-air broadcasting. It is the maximum possible in view of spectrum limitations and reservations and the present state of technology. The present policy thus has as its outer boundary an average of four to six commercial and one to two educational channels, with the larger markets slightly exceeding these figures and the smaller ones falling short.

By comparison, CATV provides as many channels as wire and converters can carry. In modern CATV systems the initial capacity is twelve to twenty TV channels. This is a doubling or trebling of the availability which can be afforded off-the-air. Moreover, cables with much greater capacities are under development. Indeed, there are no limits to the channels which cable can provide, since there is no limit to the number of cables.

In summary, a policy which permitted CATV to develop rather freely would greatly increase the number of TV channels or avenues physically available in the top roo markets. With more TV channels at hand-more numerous avenues on which mass communications could take place-there would follow an increase in the volume of actual communications. Exchange of ideas, discussion of values, and the offering of information and entertainment would be facilitated. More diverse programs would result, and viewers would have greater opportunity to choose according to their preferences. We share the belief that a well-informed populace will in the long term choose intelligently for themselves as individuals and for society as well. We undertake now to elaborate upon and prove these generalizations, by analyzing what the increased capacity would mean in terms of fundamental public service criteria.

In general, the outcome of the policy under consideration should be viewed as desirable if

(I) there is an increase in the access of people, program suppliers, and advertisers to TV channels and time, as well as an increase in the number of programs actually available;

(2) the diversity of programs becomes greater, and their characteristics and qualities improve;

(3) the increase in costs to viewers, suppliers, and society, if any, is smaller than the benefits obtained;

(4) freedom and local expression are fostered, and market control is reduced; and

(5) favorable developmental trends and innovations are fostered.

We now appraise the results of the proposed policy against each of these public interest criteria. 


\section{A. Access to TV Channels and Time}

A policy in which CATV could develop rather freely would improve society's access to TV channels and time, because additional channels would be available at virtually zero marginal cost. The major question is, What potential users are not adequately served at present? In answer, the following uses are cited as examples of social needs for channels which are not now served:

(I) the dedication of a number of free or low cost channels for educational TV, public bodies, and health service;

(2) shoppers' news and other advertiser-sponsored presentations for the service area or portions thereof;

(3) the opportunity for special services for ethnic and religious groups;

(4) political presentations;

(5) civic body meetings and presentations;

(6) advisory and information activities of the municipality and its officials; and

(7) activities of local cultural groups, in music, drama, art, dance, and literature.

It is apparent that CATV would powerfully augment access of people, program suppliers, and advertisers to TV channels and time. Individuals will differ on the values they would assign to each improved access and use, but most of us would agree that there is gain from the increases viewed over-all, which, if not offset by other factors, results in a net gain for society.

\section{B. Diversity, Characteristics, and Qualities of Offerings}

The present TV offerings available in most cities span a narrower range than books or magazines, and the choices available for the viewer at any given time are quite limited. If CATV developed rather freely how would choice widen? It was pointed out earlier that initially the range of programs available to all communities would become as wide as in New York City, Los Angeles, and Chicago combined. This would occur because CATV would import the programs of the leading independent commercial and educational stations, in addition to carrying the local network, independent, and ETV stations. Perhaps the noncommercial offerings of the Canadian Broadcasting Corporation would also be imported.

An individual viewer does not have access to the whole range of programs during the entire day, week, or season. For most of his waking hours he is captive to job, school, social obligations, chores, and family. What is important to him is the array of choices during the hours when he is free to view TV. Even if there were no increase in the total array of programs available in a community, nevertheless diversity and choice for each individual would be greatly improved if that entire array were offered to him when he is free. CATV, if developed freely, has enormous capacity to enrich the menu for the individual at the time of his viewing. So long as independent stations in several cities do not show the same 
programs at the same time, then imports widen the choice for individual viewers. The same applies even to network programs. We have assumed that the local network station has simultaneous duplication protection at the time of its network broadcast. But if the same network program is then shown later or on another day in one of the major cities from which signals are being imported, CATV viewers who could not watch the inital offering can watch the import.

In a somewhat related way, the increased number and range of programs available in each hour has large significance for the r97os. Personal black and white TV sets are far less expensive than formerly, and many homes have several sets. Increased diversity and volume might induce multiple set ownership, permitting the various members of the family each to select from a wider range of offerings. Program selection and viewing would then not be limited to a family common denominator or the preference of the child who cries the loudest.

At a later stage, as the systems mature, there will be "special programs" sent in by satellite, microwave, or cable on a network, syndicated, or quasi-network basis. The originator might pay the CATV to carry these with advertisements, or the CATV might pay for the programs itself and sell spot time to advertisers. Alternatively, the CATV or other program suppliers might sell the specific programs to subscribers as so-called pay-TV for an extra fee. The methods are not mutually exclusive, and various combinations of these arrangements are possible. For program-type diversity to be greatly augmented, it is necessary to avoid a situation in which the CATV aimed only for the mass audience in order to maximize its profits and was also able to restrict competitive offerings. Common-carrier wire TV on some or all of the CATV channels would be one way to avoid this danger. It is very important and is discussed later.

Finally there is the matter of "localism," on which a good deal of evidence is at hand from present CATV systems. In their efforts to acquire franchises and customers, CATV systems can be expected to provide extensive local affairs channels and programs. These would include coverage of local activities, meetings of the city council and other municipal bodies, and college and school sports and dramatics. It also becomes possible to reach sections of cities with specific types of programming. Residents of inner city ghettos, for example, may have specialized requirements for job information and training, general education, and health. Stephen White has suggested how this kind of facility might be used in a particular community. ${ }^{29}$

This gain in "localism" would be partly offset by a possible reduction in local station broadcast activity. In the Ioo or so major TV markets, there tends to be, or is in prospect, a marginal UHF station without network affiliation. For such a station, already barely viable, the reduction in number of viewers attributable to the CATV's increase in the total offerings might be a severe blow. Since ad-

\footnotetext{
${ }^{20}$ White, Toward a Modest Experiment in Cable Television, PuB. INTErest, Summer 1968, at 52.
} 
vertisers conventionally pay according to the size of the audience, its revenues would fall. In each such market, the unaffiliated UHF station is, if marginal, at risk and might fail. A similar possibility relates to the local educational station, if there is one. Many of these are very weak in finances and offerings. If the imported ETV programs are frequent and of quality, as is likely, then viewing of the local ETV station might fall off, along with its local financial support. Among the possible results of this would be (I) that the station would go dark; (2) that networking of educational stations would increase; (3) that the station would turn wholly to instructional programs and school system financial support; and/or (4) that the station would go entirely onto the wire in order to save about $\$ 2,000$ per week in transmission cost.

\section{Costs}

What costs are associated with the policy of permitting CATV to develop rather freely and deriving the net benefits therefrom, as compared with continuing the present policy of restricting CATV and wire pay-TV and further encouraging over-the-air television? The first thing that must be said is that no viewer incurs any cost unless he chooses. On this test any costs which a rational and informed viewer incurs would yield personal benefits greater than the outlays.

In Table $\mathrm{I}$ we summarize the cost conditions for consumers which would develop under the FCC's present anti-CATV policy as opposed to one in which CATV was permitted free development and charged $\$ 5$ monthly for service plus an installation charge. Roughly, it would cost a family $\$ 32$ per year, or about $\$ 2.5^{\circ}$ to $\$ 3$ per month, to have CATV and its services in addition to the over-the-air service. This is about one-third more than its present cost of TV service, so that the expansion of TV programs and services from CATV results in a net cost of about half of the \$5 monthly service charge.

We assumed earlier that there might be roo fewer unaffliated UHF stations in the top Ioo markets if CATV were permitted to develop rather freely. Their services would be lost, and of course their costs of operation would disappear also. There would also be liberation for other uses of the UHF spectrum now assigned to these TV channels, and some additional gains from the associated "taboo" channels. The electromagnetic spectrum is presently in short supply-for example, use by police and fire departments and other mobile services is severely restricted. A CATV-induced gain in spectrum space would be believed by some to be very important for society.

If instructional television were to utilize free or very low cost carriage on CATV, there would be a significant saving (almost $\$ 100,000$ per year per station relative to its over-the-air transmission cost) for that segment of broadcasting. 
TABLE I

Television Cost Conditions With and Without CATV

\begin{tabular}{|c|c|c|}
\hline Capital charges & $\begin{array}{c}\text { Present policies- } \\
\text { no } C A T V\end{array}$ & $\begin{array}{c}\text { If } C A T V \text { were } \\
\text { permitted to } \\
\text { develop freely }\end{array}$ \\
\hline Cost of TV sets, average & $\$ 200$ & $\$ 150^{*}$ \\
\hline Outside antenna, if any & 60 & 0 \\
\hline \multirow[t]{2}{*}{ Drop line installation } & 0 & 20 \\
\hline & $\$ 260$ & $\$ 170$ \\
\hline \multicolumn{3}{|l|}{ Annual charges } \\
\hline Electricity & 18 & I8 \\
\hline Maintenance & 30 & 20 \\
\hline CATV system charge & 0 & 60 \\
\hline \multirow[t]{2}{*}{$20 \%$ of above capital charges } & $5^{2}$ & 34 \\
\hline & $\$ 100$ & $\$ 132$ \\
\hline
\end{tabular}

* Sets designed for cable use could be about $25 \%$ cheaper, due to the elimination or reduction of the IF circuit. It is assumed that the cost of the cable-TV tuner and converter is equal to the present cost of VHF and UHF tuners.

\section{Market Control}

Present oligopoly control in local television markets would be very significantly reduced by the development of CATV and common carrier channels, and viewers would have access to many more programs. However, network oligopoly power would be reduced only moderately. As noted earlier, the network organizations have preferred positions because of their financial and program strength and their local outlets. Just as in New York, Los Angeles, and Chicago, where the networks hold far more than half the total audience, despite competition from independent stations, so they will in the contemplated new situation also.

In addition, there are clear dangers from CATV monopoly. The CATV operator might prefer certain politicians over others; could decline to import desirable stations if so doing reduced advertising sales on his own originated programs; could be uncooperative in providing time for public affairs programs if these reduced pay-TV subscriptions; and could avoid controversial offerings and people.

In the early years, a CATV's strong objective would be to sign on more subscribers. It would not decline to import good programs or fail to offer public affairs to protect its advertising revenue, because a long subscriber list would provide both revenues and potential viewers for advertising sales. Moreover, in its early years it could be vulnerable to the entrance of a competing CATV firm. In later years, however, when the subscriber list is long and durable and the advertising-sales activities financially important, the CATV might try to restrict program competition with those of its programs on which it was procuring adver- 
tising or pay-TV revenues. This is why, if CATV were permitted to develop freely, it should be with safeguards against the possibility of monopoly abuses. Among the possibilities, the following are major devices:

(I) regulation as a common carrier on some of its channels in order to ensure open access.

(2) as in Toronto and New York City, dividing the city for separate companies in order to ensure the operation of several different CATV firms. In this way, inefficiencies or abuses in one city district would become apparent through comparisons with other districts, and alternative suppliers would be available.

(3) franchise controls on rates, service, term of operation, free services for public and educational use, reversions of systems to city, dedicated channels, and so forth.

\section{E. Developmental Considerations}

Conditions for the development and implementation of technological change are improved if unused channels are deliberately fostered. Experimentation can take place on idle channels, and idle channels can be utilized to phase in new technology while existing equipment wears out. If it were decided to change to higher picture-quality standards, programs could be transmitted using both the old and the new standards until present receivers are replaced. This would make possible the introduction of the higher standards without obsoleting the public's existing investment in receivers. ${ }^{30}$

Nontelevision uses of broadband services would be fostered. These include traffic and other surveillance, data bank access, and facsimile reproduction. Low cost access to channels provides opportunity for innovation, experimentation, and other competitive phenomena. Moreover, to the extent spectrum space is released from television, more would be available for other important services, such as police and fire protection.

\section{VII}

\section{Conclusions}

The CATV innovation can multiply manyfold the number of available TV channels. Along with the innovations in satellite transmission, entertainment libraries, and public-service programs, there is now a great opportunity to improve television. There is opportunity for CATV offerings to flourish and eventually expand into the far more plentiful services of the wired city and nation. From the

\footnotetext{
${ }^{30}$ On November 15, 1969, in the United Kingdom, for example, BBC-I and ITV began broadcasting higher quality color pictures on unused UHF channels, while continuing to broadcast the same programs on the present VHF channels with the present lesser quality pictures. When VHF receivers wear out, the latter programs will be discontinued and the VHF spectrum reclaimed for other valuable uses.
} 
spur of competition would also come improved services from television stations. While some marginal or inept stations would not survive, the TV networks and the bulk of TV stations could vigorously and effectively compete.

The FCC, though long concerned about too few television offerings in each community, has difficulty adapting to the concepts of cable technology. The FCC's thinking solidified before the advent of CATV into a commitment to over-the-air stations, specifically an increase in UHF stations. At the present, the FCC only sees (correctly) that CATV is a competitor to UHF stations which are without network affiliation. But the Commission fails to see how amply and well the public could be served by the entrance of such unplanned and unanticipated suppliers. The present FCC policies are to restrict CATV and the competitive enlargement of the market which it promises. ${ }^{31}$ But hopefully the FCC will change its present rules as the result of public debate and evidence as well as of changes in its membership.

Even if the FCC were to move in this direction, there are two major and serious dangers to the vigorous development of the wired city. The first is collusory agreement between the broadcasting industry and the CATV industry. One such agreement was already proposed by their trade associations, the National Association of Broadcasters and the National Cable Television Association, which would have effectively prevented CATV program imports into the larger cities, greatly restricted program originations, and prevented CATV networks. It was a callous cartel arrangement, contemptuous of public welfare.

The second danger is that too much cross-media ownership, chain ownership, and market control will develop among broadcasters, CATV firms, newspapers, and entertainment firms. This could greatly reduce the incentives and vigor of CATV development and the public service response of its competitors. It could also obstruct the provision of a plentiful supply of low-cost common carrier channels in the wired city, conveniently available for local services, pay-TV, and diverse offerings. This obstruction, and that of competition in general, is, in fact, a major objective of the collusory agreements and other efforts at market control. These dangers could be avoided by the requirement of common carrier operation on some of the channels of the initial wire and, as needed, on additional wires, to ensure open access to television channels by all types of program suppliers.

The CATV innovation on its twenty or more initial channels would greatly increase opportunities for local advertisers and smaller national firms which are now frozen out by limited time availabilities and high charges on present stations. But it would be very unfortunate if, as is now the case on broadcast stations, advertising volume is permitted to grow to as much as thirty per cent of the program's time, with clamorous and disturbing interruptions to program continuity. This is

\footnotetext{
${ }^{31}$ For a critical discussion of the FCC's UHF policy, see Webbink, The Impact of UHF Promotion: The All-Channel Television Receiver Law, in this symposium, p. 535.
} 
a heavy and sometimes abusive price the viewer pays for his programs. At present the only way for the viewer to escape inundation by the advertising barrage is to greatly reduce his watching of TV. But if CATV were to flourish and the wired city were to develop, then programs would become more plentiful and more diverse, and the incentive to watch TV would become greater. Hopefully the high cost paid in suffering through advertising pressures could be reduced by confining advertisements to natural breaks and less frequent intervals, by limiting the volume to, say, five or ten per cent of program time, and by making available pay-TV channels with little or no advertising.

Even apart from advertising abuse, this nation's television performance falls far short of a magnificent potential. There is not each day and each week, at convenient times, great drama, literature, and music, nor challenging informational, educational, and public service programs. Because of large captive audiences, heavy advertising purses, and too little competition, television stations enjoy monopoly profits and a quiet life. More competition is needed to force them to stretch their minds and widen their visions.

Finally, it should be recognized that our analysis of the television industry's future under conditions of greater freedom for CATV systems is subject to substantial uncertainty. Some of this uncertainty, such as the CATV impact on independent UHF stations or the costs of wiring, can be reduced by research utilizing data collected by the FCC. In other cases, the uncertainty is not so easily reduced; it is perhaps necessary to follow the implications of alternative assumptions to see how greatly the outcome is affected. This approach is more likely to lead to economic and political freedoms which serve the public well than will agreements for a cartel-like peace between the broadcaster and the CATV systems, even if these agreements are given the force of law by the FCC or Congress. 